\title{
Type I Collagen C-Telopeptide to Creatinine Ratio Measurement
}

National Cancer Institute

\section{Source}

National Cancer Institute. Type I Collagen C-Telopeptide to Creatinine Ratio

Measurement. NCI Thesaurus. Code C127613.

The determination of the ratio of type I collagen c-telopeptides compared to creatinine present in a sample. The measurement may be expressed as a ratio or percentage. 